\title{
Performance Evaluation of Reworked Weld Joints
}

\section{Sivarao ${ }^{1,}$ a, Aidy Ali ${ }^{2, b^{*}}$, Mohd Amran ${ }^{1, c}$, L.D. Sivakumar ${ }^{3, d}$, Shukor Salleh ${ }^{1, e}$, and Rajaizam ${ }^{1, f}$}

\author{
${ }^{1}$ Faculty of Manufacturing Engineering, Universiti Teknikal Malaysia Melaka (UTeM), \\ 75450 Ayer Keroh, Melaka, Malaysia. \\ ${ }^{2}$ Department of Mechanical Engineering, Faculty of Engineering, \\ Universiti Pertahanan Nasional Malaysia (UPNM), Kem Sg. Besi, 57000 Kuala Lumpur, Malaysia \\ ${ }^{3}$ Faculty of Mechanical Engineering, Universiti Teknikal Malaysia Melaka, \\ Universiti Teknikal Malaysia Melaka,(UTeM), \\ 75450 Ayer Keroh, Melaka, Malaysia. \\ asivarao@utem.edu.my, bsaidynaidy@gmail.com, cmohdamran@gmail.com, \\ dsivakumard@utem.edu.my, e'shukor@utem.edu.my, fizamshah@gmail.com
}

Keywords: Shielded metal arc welding; Carbon steel; Mechanical properties.

\begin{abstract}
This study presents the performance evaluation of reworked welded joint that have weld imperfections which may result the strength of the structures. Tensile, bending and shear tests have been performed to evaluate the performance and reliability of reworked joint. Their effects on the quality and performance of the reworked welded joint are depend on the requirements of the structure in use. This study is providing detailed examination of the mechanical properties of the carbon steel reworked welded joint by using shielded metal arc welding (SMAW) techniques.
\end{abstract}

\section{Introduction}

Welding is one of the most important technological processes used across numerous branches of industry such as industrial engineering, shipbuilding, and pipeline fabrication. Unfortunately, the thermal effect of the welding process sometimes produces hard and brittle microstructure which affects adversely the mechanical properties [1]. In Shielded Metal Arc Welding (SMAW) process, the heat for welding is generated by an arc established between a flux-covered consumable electrode and the workpiece. The core wire conducts the electric current to the arc and provides filler metal for the joint. The heat of the arc melts the core wire and the flux covering at the electrode tip into metal droplets. Molten metal in the weld pool solidifies into the weld metal while the lighter molten flux floats on the top surface and solidifies as a slag layer. The weld area is protected by a gaseous shield obtained from the combustion of the flux [2].

After rework, there is always the unspoken question of the potentially adverse effect of the rework on product reliability, especially where uncontrolled hand processes are used. Engineering intuition is that a reworked joint will be less reliable than one which has not been reworked. The advantages of welding, as a joining process, include high joint efficiency, simple set up, flexibility and low fabrication costs [3]. Welding input parameters play a very significant role in determining the quality of a weld joint. The joint quality can be defined in terms of properties such as weld-bead geometry, mechanical properties, and distortion [4].

Generally, all welding processes are used with the aim of obtaining a welded joint with the desired weld-bead parameters, excellent mechanical properties with minimum distortion [5]. The main purpose of determining the performance evaluation on reworked welding joint is in order to determine the strength and stress of the welded joint upon applying force gradually.

The reliability and safe operation of oil and gas infrastructure is heavily dependent on the structural integrity of its welded joints. The quality of these joints must be assessed from the pipe mills and fabrication yard to the end of the operating life of the pressure vessel or piping system.

Due to limited information on the mechanical properties of carbon steel of reworked joints, therefore this study is undertaken on rework process in shielded metal-arc welding (SMAW) on 
some mechanical properties of carbon steel weld. Carbon steel was used for this study because of it is accounts for about $90 \%$ of total plain carbon steel and is widely applied due to their economic value, excellent weldability, good mechanical and physical properties acceptable to many applications [6]. The beauty of this study, we also look into the influence of reworked joint on the tensile test, bending test and shear test of welded carbon steel.

\section{Materials and method}

The investigated research work was conducted on $3 \mathrm{~mm}, 4.5 \mathrm{~mm}$, and $5 \mathrm{~mm}$ carbon steel was welded by using Shielded Metal Arc Welding (SMAW). Welding current of 90 A were used with E6013 consumable electrodes. Types of welding joint for each testing are shown in Table 1. Testing specimens ware prepared according to ASTM E290-13 standard for bending test, ASTM E8/E8M-13a standard for tensile test, and ASTM D1002-10 for shear test. The critical methodology of the entire research is shown in Figure 1.

Table 1. Types of welding joint.

\begin{tabular}{|l|l|}
\hline Testing Method & Types of Welding Joint \\
\hline Tensile Test & Butt Joint \\
\hline Bending Test & Butt Joint \\
\hline Shear Test & Lap Joint \\
\hline
\end{tabular}

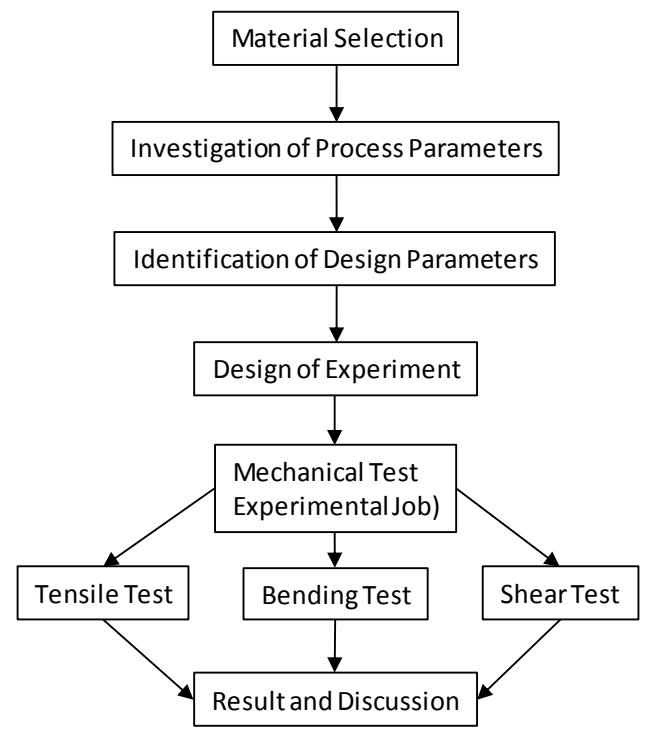

Figure 1. Flow Chart.

Tensile test is a very fundamental type of mechanical test that can perform on material. By pulling on specimen, it can determine how materials react to force being applied in tension. As it continues to pull on specimen until it breaks, a good and complete tensile profile obtained. This testing method enable to identify extension of force applied. Speed applied for this testing is $4 \mathrm{~mm} / \mathrm{min}$.

Shear test is used to determine the load at which a plastic or film will yield when sheared between two metal edges. It is important to determine where applied crushing loads are a risk. The area of testing is applied at the centre of specimen for a better result. Speed applied for this testing is $4 \mathrm{~mm} / \mathrm{min}$.

3 Point Bending test is commonly used to measure flexural modulus, flexural strength, and yield point are the common key analysis. Flexural modulus is to measure the stiffness of specimen, 
flexural strength is to measure maximum force that specimen can withstand, and yield point is the point where if you were continue to bend the specimen. The most common test method used is 3 point bending.

\section{Results and Discussion}

The tensile, bending and shear test for each reworked stage are presented in Table 2 - 10 respectively. After the weld has been completed, the plate was left to cool down to the ambient temperature. Following that, various types of mechanical tests were selected to evaluate and compare the effect of reworked on the mechanical properties.

\subsection{Tensile Test}

According to Table 2, first specimen of $3 \mathrm{~mm}$ thickness could stand the load of $33.52 \mathrm{kN}$ for an extension about $0.89 \mathrm{~mm}$ while $5 \mathrm{~mm}$ thickness plate could stand the load of $62.63 \mathrm{kN}$ for an extension about $1.19 \mathrm{~mm}$. Both thickness plates are welded from new plate without any rework. The tensile stress produced due to maximum load is about $0.22 \mathrm{GPa}$ for the $3 \mathrm{~mm}$ thickness of plate while $0.28 \mathrm{GPa}$ for the $5 \mathrm{~mm}$ thickness of plate. The yield strength is very vital for the purpose of engineering structural design since the sample shows significant plastic deformation.

Table 2. Tensile Specimen 1 (Normal Welding).

\begin{tabular}{|l|c|c|}
\hline \multicolumn{1}{|c|}{ Results } & $3 \mathrm{~mm}$ & $5 \mathrm{~mm}$ \\
\hline Max. Load on Specimen $(\mathrm{kN})$ & 33.52 & 62.63 \\
\hline Tensile Stress at Max. Load $(\mathrm{GPa})$ & 0.22 & 0.28 \\
\hline Extension at Max. Load (mm) & 0.89 & 1.19 \\
\hline Tensile Stress at Yield Load (GPa) & 0.22 & 0.28 \\
\hline
\end{tabular}

As shown in Table 3, second specimen with $3 \mathrm{~mm}$ thickness stands the load of $30.94 \mathrm{kN}$ for an extension about $0.70 \mathrm{~mm}$ while $5 \mathrm{~mm}$ thickness plate could stand the load of $58.76 \mathrm{kN}$ of load for an extension about $1.07 \mathrm{~mm}$. Both thickness plates are known as reworked welding for $1 \mathrm{st}$ time which means the plates are welded initially then the plates are cut using grinder then finally welded back. The tensile stress produced due to maximum load is about $0.21 \mathrm{GPa}$ for the $3 \mathrm{~mm}$ thickness of plate while $0.26 \mathrm{GPa}$ for the $5 \mathrm{~mm}$ thickness of plate.

Table 3. Tensile Specimen 2 (Reworked for 1st time).

\begin{tabular}{|l|c|c|}
\hline \multicolumn{1}{|c|}{ Results } & $3 \mathrm{~mm}$ & $5 \mathrm{~mm}$ \\
\hline Max. Load on Specimen (kN) & 30.94 & 58.76 \\
\hline Tensile Stress at Max. Load (mm) & 0.21 & 0.26 \\
\hline Extension at Max. Load (mm) & 0.70 & 1.07 \\
\hline Tensile Stress at Yield Load (GPa) & 0.21 & 0.26 \\
\hline
\end{tabular}

Following to Table 4, third specimen of $3 \mathrm{~mm}$ thickness could stand the load of $27.39 \mathrm{kN}$ as the extension is about $0.69 \mathrm{~mm}$ while $5 \mathrm{~mm}$ thickness plate could stand the load of $39.28 \mathrm{kN}$ with an extension about $0.56 \mathrm{~mm}$. Both of thickness plates are known as reworked welding for 2 nd time which means the plates are welded initially then the plates are cut using a grinder then finally welded back. The process is repeated for one more time. The tensile stress produced due to maximum load is about $0.21 \mathrm{GPa}$ for the $3 \mathrm{~mm}$ thickness of plate while $0.26 \mathrm{GPa}$ for the $5 \mathrm{~mm}$ thickness of plate. 
Table 4. Tensile Specimen 3 (Reworked for 2nd time).

\begin{tabular}{|l|c|c|}
\hline \multicolumn{1}{|c|}{ Results } & $3 \mathrm{~mm}$ & $5 \mathrm{~mm}$ \\
\hline Max. Load on Specimen (kN) & 27.39 & 39.28 \\
\hline Tensile Stress at Max. Load (mm) & 0.18 & 0.17 \\
\hline Extension at Max. Load (mm) & 0.69 & 0.56 \\
\hline Tensile Stress at Yield Load (GPa) & 0.18 & 0.17 \\
\hline
\end{tabular}

\subsection{Bending Test}

Table 5 shows the result of 3 Point Bending Test for butt joint specimen. First specimen of $3 \mathrm{~mm}$ thickness could stand the load of $22.38 \mathrm{kN}$ for an extension about $1.09 \mathrm{~mm}$ while $4.5 \mathrm{~mm}$ thickness plate could stand the load of $34.06 \mathrm{kN}$ for an extension is about $2.46 \mathrm{~mm}$. Both thickness plates are welded from new plate without any rework. The maximum stress produced due to maximum load is about $242.36 \mathrm{~N} / \mathrm{mm} 2$ for the $3 \mathrm{~mm}$ thickness of plate while the maximum load of $547.22 \mathrm{~N} / \mathrm{mm} 2$ for the $4.5 \mathrm{~mm}$ thickness of plate.

Table 5. Bending Specimen 1 (Normal Welding).

\begin{tabular}{|l|c|c|}
\hline \multicolumn{1}{|c|}{ Results } & $3 \mathrm{~mm}$ & $5 \mathrm{~mm}$ \\
\hline Max. Load on Specimen (kN) & 22.38 & 34.06 \\
\hline Max. Stress (N/mm2) & 242.36 & 547.22 \\
\hline Extension at Max. Load (mm) & 1.09 & 2.46 \\
\hline Max. Strain (\%) & 3.25 & 4.09 \\
\hline
\end{tabular}

Second specimen of $3 \mathrm{~mm}$ thickness stands the load of $21.52 \mathrm{kN}$ for a maximum extension about $1.03 \mathrm{~mm}$ while $4.5 \mathrm{~mm}$ thickness plate could stand the load of $26.90 \mathrm{kN}$ for a maximum extension about $2.08 \mathrm{~mm}$ as indicated in Table 6. Both thickness plates are known as reworked welding for 1st time which means the plates are welded initially then the plates are cut using a grinder and finally welded back again. The maximum stress maximum stress produced due to maximum load is about $241.78 \mathrm{~N} / \mathrm{mm} 2$ for the $3 \mathrm{~mm}$ thickness of plate while $460.22 \mathrm{~N} / \mathrm{mm} 2$ for the $4.5 \mathrm{~mm}$ thickness of plate. The percentages of strain for both plates are $2.58 \%$ for $3 \mathrm{~mm}$ thickness and $2.69 \%$ for $4.5 \mathrm{~mm}$ thickness.

Table 6. Bending Specimen 2 (Reworked for 1st time).

\begin{tabular}{|l|c|c|}
\hline \multicolumn{1}{|c|}{ Results } & $3 \mathrm{~mm}$ & $5 \mathrm{~mm}$ \\
\hline Max. Load on Specimen (kN) & 21.52 & 26.90 \\
\hline Max. Stress (N/mm2) & 241.78 & 460.22 \\
\hline Extension at Max. Load (mm) & 1.03 & 2.08 \\
\hline Max. Strain (\%) & 2.58 & 2.69 \\
\hline
\end{tabular}

Third specimen of $3 \mathrm{~mm}$ thickness could stand the maximum load of $20.57 \mathrm{kN}$ for a maximum extension about $0.54 \mathrm{~mm}$ while $4.5 \mathrm{~mm}$ thickness plate could stand the maximum load of $20.95 \mathrm{kN}$ for a maximum of extension $1.68 \mathrm{~mm}$ as shown in Table 7. Both thickness plates are known as reworked welding for 2 nd time which means the plate are welded initially then the plates are cut using grinder then finally welded back. This process is repeated for one more time. The maximum stress produced due to maximum load is about $119.44 \mathrm{~N} / \mathrm{mm} 2$ for the $3 \mathrm{~mm}$ thickness of plate while $403.23 \mathrm{~N} / \mathrm{mm} 2$ for the $4.5 \mathrm{~mm}$ thickness of plate. The percentages of maximum strain obtained are $2.46 \%$ for plate of $3 \mathrm{~mm}$ thickness and $2.51 \%$ for the plate of $4.5 \mathrm{~mm}$ thickness. 
Table 7. Bending Specimen 3 (Reworked for 2nd time).

\begin{tabular}{|l|l|l|}
\hline \multicolumn{1}{|c|}{ Results } & \multicolumn{1}{|c|}{$3 \mathrm{~mm}$} & $4.5 \mathrm{~mm}$ \\
\hline Max. Load on Specimen (kN) & 20.57 & 20.95 \\
\hline Max. Stress (N/mm2) & 119.44 & 403.23 \\
\hline Extension at Max. Load (mm) & 0.54 & 1.68 \\
\hline Max. Strain (\%) & 2.47 & 2.51 \\
\hline
\end{tabular}

\subsection{Shear Test}

According to Table 8, first specimen with $3 \mathrm{~mm}$ thickness could stand the shear load of $14.94 \mathrm{kN}$ for an extension about $0.74 \mathrm{~mm}$ while $4.5 \mathrm{~mm}$ thickness plate could stand the load of $29.48 \mathrm{kN}$ of load for an extension about $2.65 \mathrm{~mm}$. Both thickness plates are welded from the new plate without any rework. The maximum stress produced due to maximum load is about $0.10 \mathrm{GPa}$ for the $3 \mathrm{~mm}$ thickness of plate while the maximum load of $0.12 \mathrm{GPa}$ for the $4.5 \mathrm{~mm}$ thickness.

Second specimen with $3 \mathrm{~mm}$ thickness could stand the load of $14.41 \mathrm{kN}$ for a maximum extension about $0.63 \mathrm{~mm}$ while $4.5 \mathrm{~mm}$ thickness plate could stand the load of $16.35 \mathrm{kN}$ of load for a maximum extension about $1.02 \mathrm{~mm}$ as indicated in Table 9. Both thickness plates are known as reworked welding for 1st time which means the plates are welded initially then the plates are cut using grinder then finally welded back again. The maximum stress produced due to maximum load. is about $0.06 \mathrm{GPa}$ for the $3 \mathrm{~mm}$ thickness of plate while $0.11 \mathrm{GPa}$ for the $4.5 \mathrm{~mm}$ thickness of plate.

Table 8. Shear Specimen 1 (Normal Welding).

\begin{tabular}{|l|c|c|}
\hline \multicolumn{1}{|c|}{ Results } & $3 \mathrm{~mm}$ & $4.5 \mathrm{~mm}$ \\
\hline Max. Load on Specimen $(\mathrm{kN})$ & 14.94 & 29.48 \\
\hline Tensile Stress at Max. Load $(\mathrm{GPa})$ & 0.10 & 0.12 \\
\hline Extension at Max. Load $(\mathrm{mm})$ & 0.74 & 2.65 \\
\hline Tensile Stress at Yield Load $(\mathrm{GPa})$ & 0.10 & 0.12 \\
\hline
\end{tabular}

Table 9. Bending Specimen 2 (Reworked for 1st time).

\begin{tabular}{|l|c|c|}
\hline \multicolumn{1}{|c|}{ Results } & $3 \mathrm{~mm}$ & $4.5 \mathrm{~mm}$ \\
\hline Max. Load on Specimen (kN) & 14.41 & 16.35 \\
\hline Tensile Stress at Max. Load (GPa) & 0.06 & 0.11 \\
\hline Extension at Max. Load (mm) & 0.63 & 1.02 \\
\hline Tensile Stress at Yield Load (GPa) & 14.41 & 16.35 \\
\hline
\end{tabular}

As shown in Table 10, third specimen of $3 \mathrm{~mm}$ thickness could stand the maximum load of $9.72 \mathrm{kN}$ for a maximum extension about $0.49 \mathrm{~mm}$ while $4.5 \mathrm{~mm}$ thickness plate could stand the maximum load of $16.30 \mathrm{kN}$ of load for a maximum extension about $0.52 \mathrm{~mm}$. Both thickness plates are known as reworked welding for 2 nd time which means the plate are welded initially then the plates are cut using grinder then finally welded back. This process is repeated for one more time. The maximum stress produced due to maximum load is about $0.06 \mathrm{GPa}$ for the $3 \mathrm{~mm}$ thickness of plate while $0.07 \mathrm{GPa}$ for the $4.5 \mathrm{~mm}$ thickness of plate. 
Table 10. Shear Specimen 3 (Reworked for 2nd time).

\begin{tabular}{|l|c|c|}
\hline \multicolumn{1}{|c|}{ Results } & $3 \mathrm{~mm}$ & $4.5 \mathrm{~mm}$ \\
\hline Max. Load on Specimen (kN) & 9.72 & 16.30 \\
\hline Tensile Stress at Max. Load (GPa) & 0.06 & 0.07 \\
\hline Extension at Max. Load (mm) & 0.49 & 0.52 \\
\hline Tensile Stress at Yield Load (GPa) & 0.06 & 0.07 \\
\hline
\end{tabular}

From the Figure 2 to 4 shows that the maximum load decreases from specimen 1 to specimen 3. The highest load since there is no changes in microstructure properties on the normal welding joints. The performance in terms of strength of reworked welding is reducing upon increasing of the number of reworked process on welding joints which can be observed from the preliminary test. During the reworked process, the microstructure of metal will be changed due to high temperature of reworked welding heat which reduced the original properties of metal joints. The reworked welding process will reduce the strength in main support of metal joint which will cause deterioration to the entire structure. The other possible factors which affect the performance of welding joints are the quantitative welding parameters such as current setting, welding electrode size and type of welding machine as well as the qualitative factors such as welding skill, welding consistency and workplace environment.

The strength of welding joint is decreasing upon increase of number welding process. The microstructure of the welding joint will become weak due to rework process as well will result fracture at welding joints. A repair is rework but rework is not always a repair. A weld repair brings the weld back into specification. Rework can have other causes such as manufacturing error, design error and many more which can result in an acceptable weld being carried out again. Rework process are expensive and often detract from the appearance of the final weld. Review every flaw and defect in the weld, regardless of its severity, to determine its cause. Future to eliminate similar problems, repair or reworked review should include the following areas:

a) Appropriate base material; proper tooling;

b) preparation for welding;

c) joint preparation; process application (welding variables);

d) welder training and skill. 


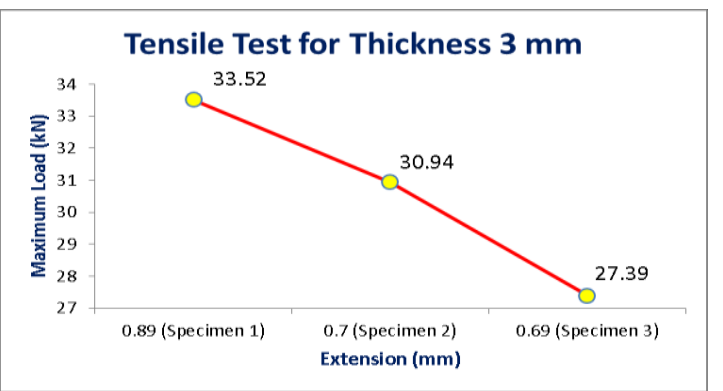

(a)

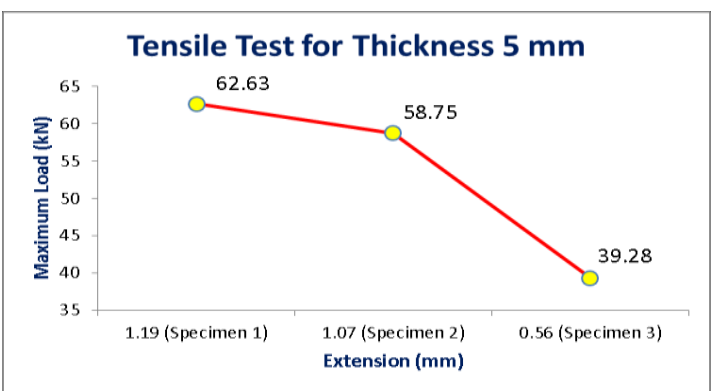

(b)

Figure 2. Maximum load (kN) versus extension (mm); (a) $3 \mathrm{~mm}$ and (b) $5 \mathrm{~mm}$.

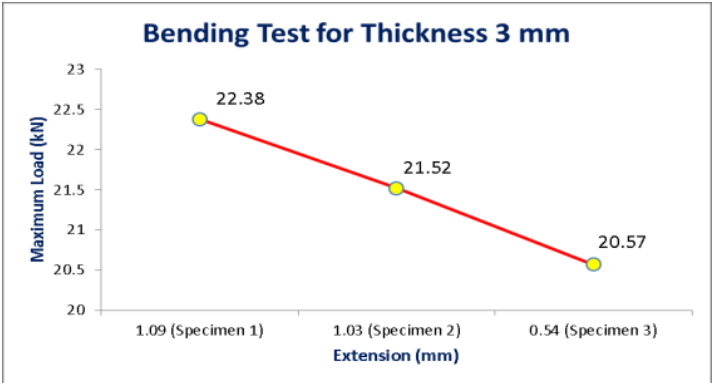

(a)

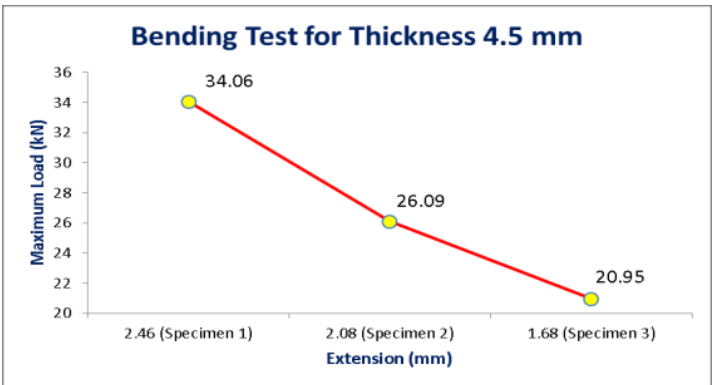

(b)

Figure 3. Maximum load ( $\mathrm{kN}$ ) versus extension (mm): (a) $3 \mathrm{~mm}$ and (b) $4.5 \mathrm{~mm}$. 


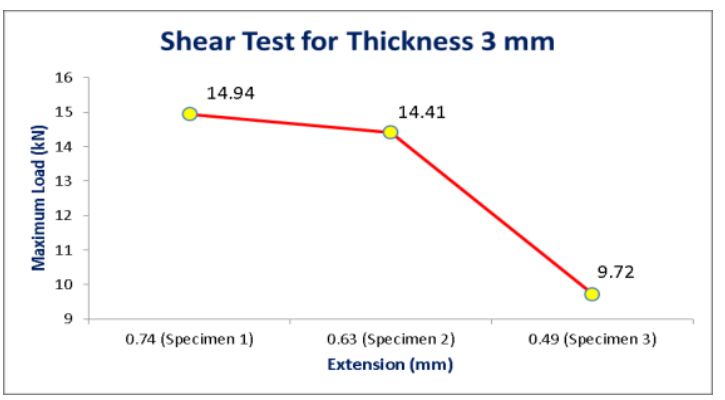

(a)

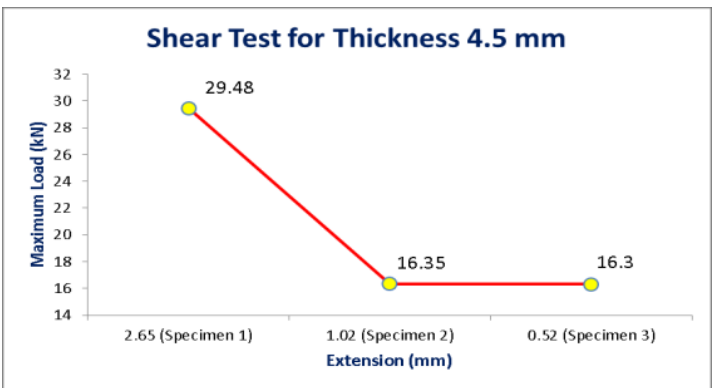

(b)

Figure 4. Maximum load (kN) versus extension (mm): (a) $3 \mathrm{~mm}$ and (b) $4.5 \mathrm{~mm}$.

\section{Conclusions}

In this article, the effect of SMAW on the mechanical properties of $3 \mathrm{~mm}, 4.5 \mathrm{~mm}$ and $5 \mathrm{~mm}$ thick carbon steel was investigated. The SMAW process was carried out by normal welding, first rework and second rework. The reworked welding joint in carbon steel were reduced the performance in terms of strength and reliability of welded joints. The strength of carbon steel was gradually decreased upon increasing the number of rework process. Rework welding process will result failure on welding joints if several rework process is carried out. As a result, the strength and the mechanical properties of the welding joints will be affected and finally will cause the failure to the entire mechanical structure.

\section{References}

[1] Welding Technology Institute of Australia, Post weld heat treatment of welded structures, Guidance Note 6, Welding Technology Institute of Australia, Australia, 2003.

[2] R.W. Messler, Joining of materials and structures, Burlington: Butterworth-Heinemann, 2004.

[3] R. Sudhakaran, V. Vel-Murugan, P.S. Sivasakthivel, Effect of Process Parameters on Depth of Penetration in Gas Tungsten Arc Welded (GTAW) 202 Grade Stainless Steel Plates Using Response Surface Methodology, Journal of Engineering Research. 9(1) (2012) 64-79.

[4] R. Khan, Anisotropic deformation behavior of A12024T351 aluminium alloy, The Journal of Engineering Research. 10(1) (2013) 80-87.

[5] E.A. Al-Bahkali, Load-displacement curves of spot welded, bonded, and weld-bonded joints for dissimilar materials and thickness, The Journal of Engineering Research. 8(2) (2011) 32-39.

[6] T.V. Rajan, C.P. Sharma, A. Sharma, Heat treatment: principles and technique, $2^{\text {nd }}$ edn., New Delhi, PHI Learning Private Limited, 2011. 